\title{
I Am Number 3 or 4?: Presidential Lecture at KSELS 2019
}

\author{
Sang-Mok Lee, M.D., Ph.D.
}

Department of Surgery, Kyung Hee University College of Medicine, Seoul, Korea

Received May 21, 2019, Accepted May 29, 2019

Corresponding author

Sang-Mok Lee

Department of Surgery, Kyung Hee University College of Medicine, 26 Kyunghee-daero, Dongdaemun-gu, Seoul 02447, Korea

Tel: +82-2-961-0114, Fax: +82-2-966-9366, E-mail: hbplapa@khu.ac.kr

ORCID: https://orcid.org/0000-0002-8786-9627

This is an Open Access article distributed under the terms of the Creative Commons Attribution Non-Commercial License (http:// creativecommons.org/licenses/by-nc/4.0/) which permits unrestricted non-commercial use, distribution, and reproduction in any medium, provided the original work is properly cited.

Copyright @ 2019 The Journal of Minimally Invasive Surgery. All rights reserved.

\section{HISTORY OF MODERN LAPAROSCOPY}

Laparoscopic surgery has grown gradually out of endoscopy and arrived at its present form progressively through leaps of intuition, making it difficult to attribute credit to its discovery. ${ }^{1}$ A history of laparoscopy is the history of endoscopy and of light sources and optics. The history begins with Hippocrates (460 375 BC) who used a rectal speculum. ${ }^{2}$ Throughout the ages, the management of disease processes has been particularly exemplified in the open cavity. ${ }^{3}$ The establishment of open-cavity endoscopic procedures was followed by the development of closed-cavity endoscopy. ${ }^{2}$

Since the beginning of the $20^{\text {th }}$ century, physicians have promoted laparoscopy as a valuable adjunct to the diagnosis of diseases of the abdominal cavity. ${ }^{4}$ The first laparoscopy was carried out using a cystoscope (a rigid telescopic endoscope) with distal light illumination. ${ }^{5}$ The historical chronicle may actually provide surgeons with a secure foundation as they embark on the new era of video laparoscopy. ${ }^{6}$ In 1997, Law et al. classified the era of laparoscopic surgery into three main areas: diagnostic, therapeutic, and modern laparoscopy. ${ }^{7}$ The era of modern laparoscopy began with the invention of the charge coupled device (CCD) camera.

1. Era of Diagnostic Laparoscopy (1901 1933)

2. Era of Operative Laparoscopy (1933 1987)

\section{Modern Era of Laparoscopy (1987 to Present)}

In September 1985, a German surgeon, Erich M. Mühe, performed the first laparoscopic cholecystectomy (LC) in humans using a modified rectoscope and pistol grip instruments with an optic and $\mathrm{CO}_{2}$ insufflation in a single puncture approach in 1986 (Fig. 1). ${ }^{8}$ The CCD camera was invented in 1986. In 1987, the first video-assisted LC was performed, and a full LC

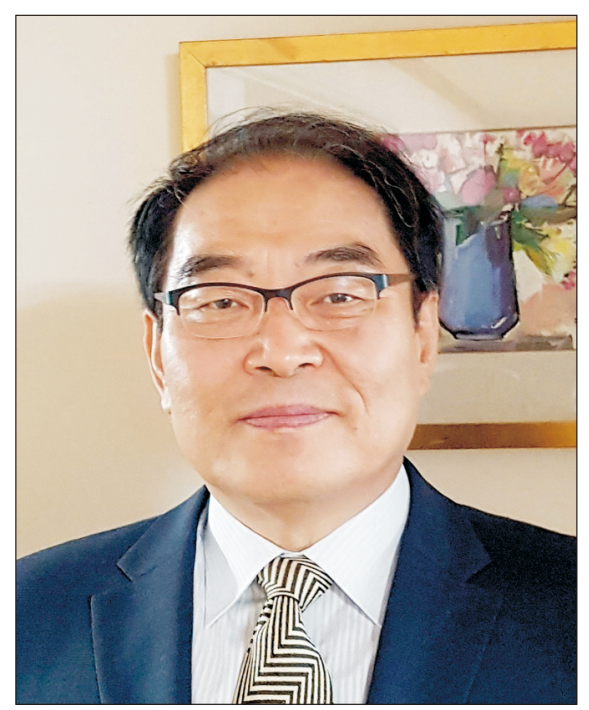




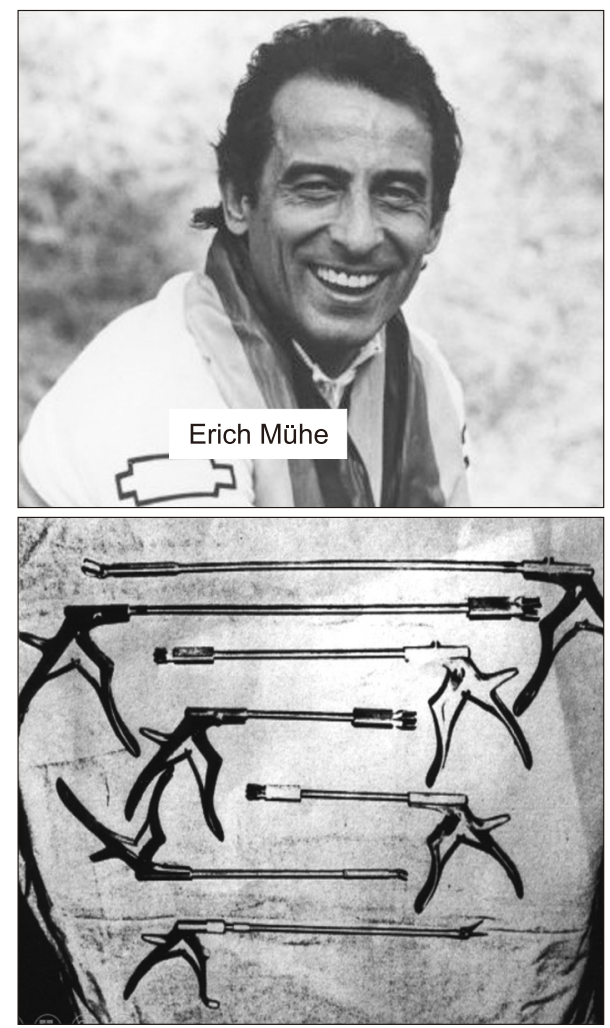

Galloscope-Laparoscope invented by Erich Mühe

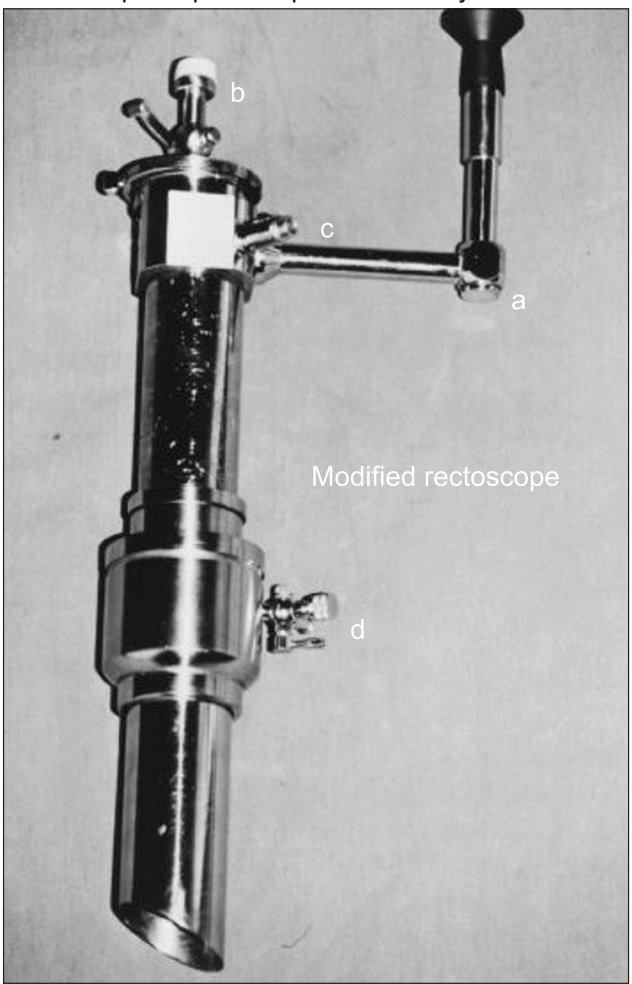

Fig. 1. German surgeon Erich M Mühe performed the first laparoscopic cholecystectomy in a human using a modified rectoscope and pistol grip instruments with an optic and $\mathrm{CO}_{2}$ insufflation. $\mathrm{a}=$ side-view optics; $b=$ instrumentation channel with valves; $c=$ light conductor; $d=$ gas channel.
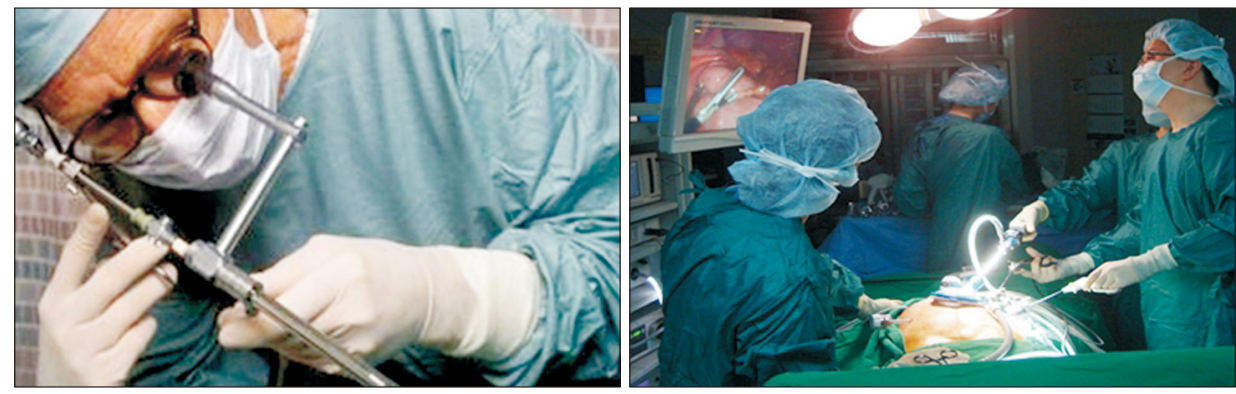

Fig. 2. (A) Side-view laparoscopy. (B) Video laparoscopy.

was performed in 1988. Using video laparoscopy, the surgeon's hand has freedom, which helped promote the widespread use of laparoscopic surgery (Fig. 2). Within a few months, laparoscopic surgery became quite popular and with academic interest and the developments from industry and medicine, the new surgical approach has evolved quickly.

\section{WEIGHT OF LAPAROSCOPIC CHOLECYSTECTOMY}

LC is a very important operation in the history of surgery. The advent of LC was a revolution of laparoscopy, from diagnosis to treatment, and was the single most important stimulus to the development of operative laparoscopy in the history of surgery. Laparoscopy, however, failed to become popular among abdominal surgeons until the advent of LC. The gen- eral surgeon has again become the leader in the introduction of this new paradigm of surgery. ${ }^{4} \mathrm{LC}$ is now used to test all types of innovations related to instruments, such as telemedicine, as well as new modes of hospitalization, such as ambulatory surgery, because LC is rather difficult but relatively common procedure.

In 1990, the first LC was performed in Seoul and in 1991 many laparoscopic surgery workshops were held. In 1996 the Korean Society for Endoscopic and Laparoscopic Surgeons were established. Since the Society was formed, there has been the rapid development of laparoscopic surgery.

In 1991, the first LC was done by Dr. Eddie J. Reddick, USA, at the authors' hospital (Kyung Hee University Medical Center, Seoul, Korea). In 1993, I successfully performed my first LC and then gradually performed advanced laparoscopic surgery (Table 1). ${ }^{9-13}$ According to the medical records of the 
first case, the gall bladder showed inflammation and omental adhesion. The operation time was 120 minutes using four trocars; the postoperative hospital stay was six days, and the

Table 1. Personal experience of laparoscopic surgery

\begin{tabular}{cl}
\hline First year & \multicolumn{1}{c}{ Procedures } \\
\hline 1993 & Cholecystectomy \\
1995 & $\begin{array}{c}\text { Splenectomy, Colectomy, Cholecystectomy } \\
\text { (acute cholecystitis) }\end{array}$ \\
& CBD exploration, Gastrojejunostomy, Hernia repair \\
1996 & Adrenalectomy \\
1997 & Needlescopic cholecystectomy \\
2002 & Hepatectomy \\
2004 & Distal pancreatectomy \\
2007 & TEP hernia repair under local anesthesia \\
\hline
\end{tabular}

$\mathrm{CBD}=$ common bile duct; TEP $=$ totally extraperitoneal . pathologic diagnosis was acute (empyema) and chronic cholecystitis (Fig. 3). In the early 1990s, acute cholecystitis was a contraindication for LC for most surgeons.

\section{BENEFITS AND FUTURE PERSPECTIVE}

Laparoscopic surgery has benefits over open surgery because of its minimal invasiveness. Recently, the cosmetic effect has been emphasized. For more benefits, new methods have appeared, such as needlescopic surgery, single incision surgery, and NOTES. While each method can increase the benefits, they have their advantages and disadvantages. Single port surgery appears to be the best method to achieve cosmetic benefits, but more patients than expected show a very good cosmetic effect when multi-port surgery is performed, particularly in patients undergoing low abdominal surgery (Fig. 4 and 5). Most patients who underwent laparoscopic totally extraperitoneal (TEP) hernia repair using three trocars showed excellent cosmetic results. On the other hand, multiple and/

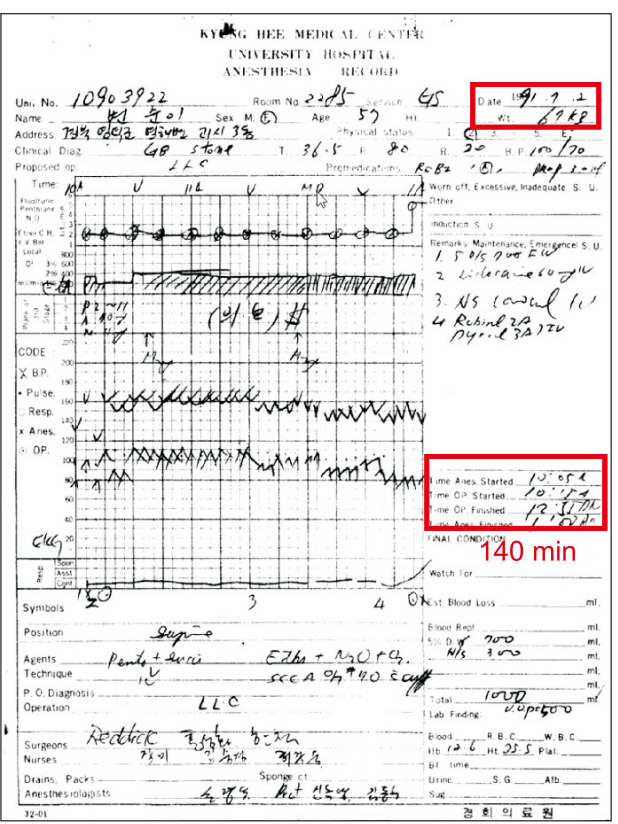

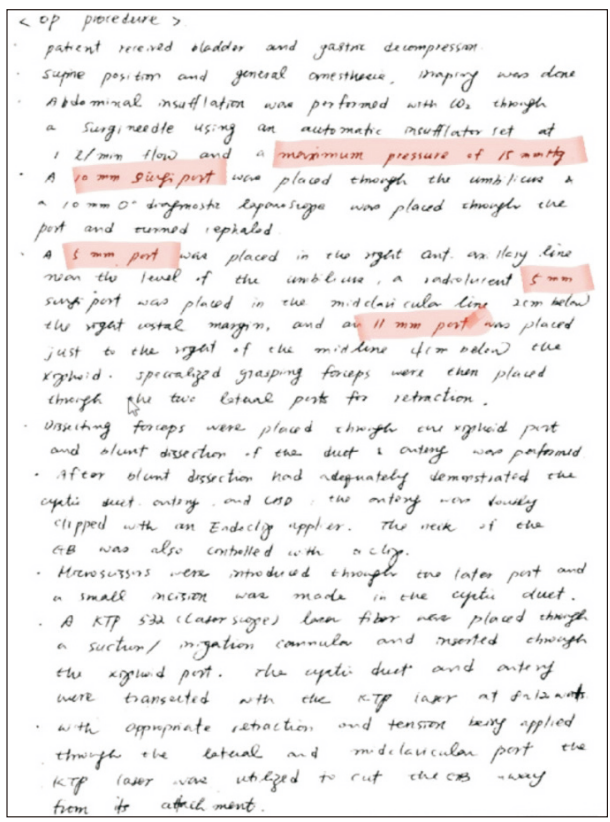

Fig. 3. Medical records of the first case at Kyung Hee University Medical Center.

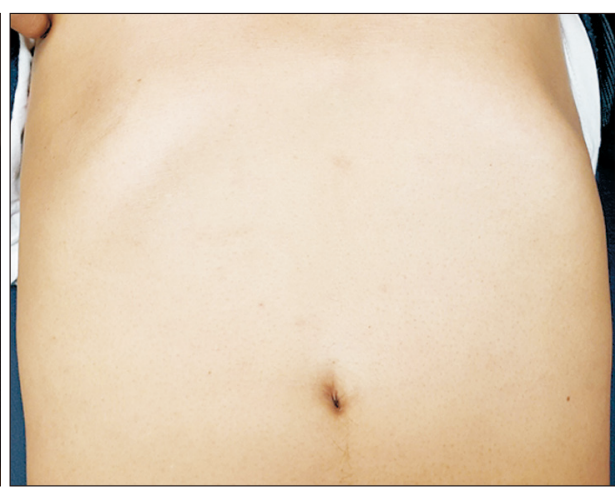

Fig. 4. Postoperative scar after laparoscopic cholecystectomy using a four trocar method (10 mm, 5 mm, $2 \mathrm{~mm} \times 2$ ). 

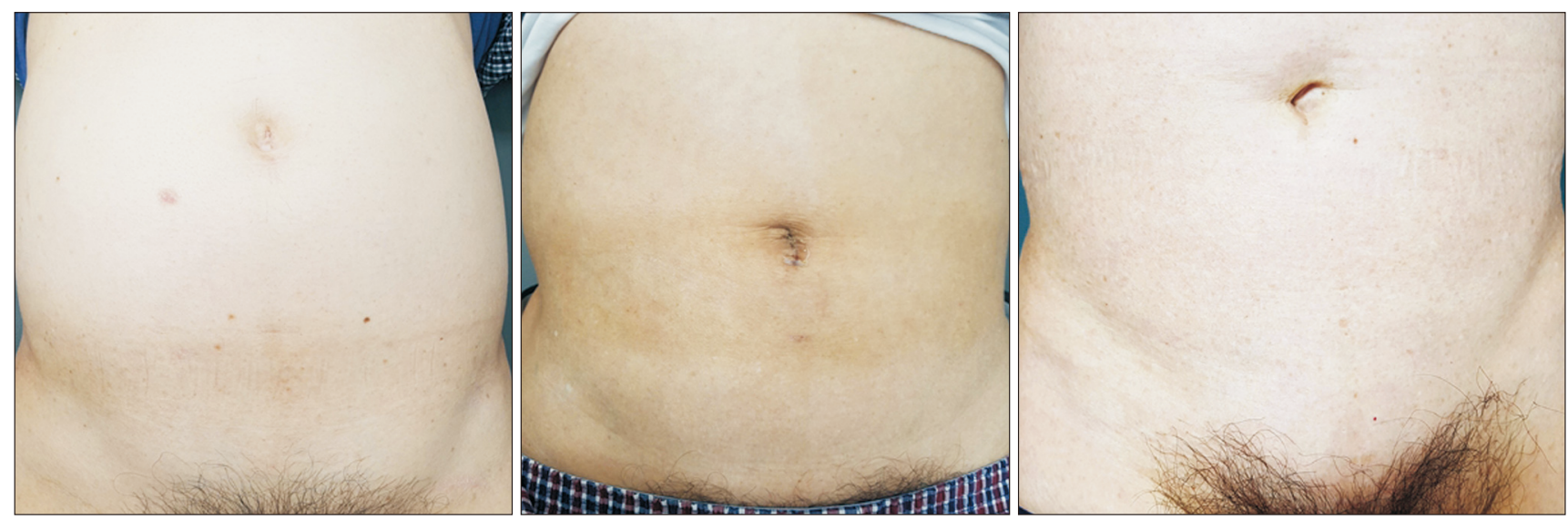

Fig. 5. Postoperative scar after laparoscopic TEP hernia repair using three trocars $(10 \mathrm{~mm}, 5 \mathrm{~mm}$ x2).

Table 2. Final destination and future requirements of laparoscopic surgery

\begin{tabular}{ll}
\hline Final destination & Future requirement \\
\hline - Short operation time & - Computer and robot \\
- No pain & - Mechanical engineering \\
- No scar & - Passion \\
- Early recovery & - Humanity \\
- No complication & \\
- Low cost & \\
- Short learning curve & \\
\hline
\end{tabular}

or large trocars are inevitably needed in patients with acute cholecystitis, with a history of previous abdominal surgery, or with large masses. Indeed, there are so many factors except for the cosmetic effect that meet the patient's satisfaction in laparoscopic surgery. The number and/or size of trocars is only a small factor in laparoscopic surgery.

What is the most important factor in laparoscopic surgery? What can satisfy the patients? What is the ultimate goal of laparoscopic surgery? How will future laparoscopic surgery be performed? All of these are complex and a mission that we need to carry out with passion and humanity (Table 2).

\section{CONFLICT OF INTEREST}

None.

\section{FUNDING}

None.

\section{ACKNOWLEDGMENTS}

None.

\section{REFERENCES}

1) Nano M. A brief history of laparoscopy. G Chir 2012;33:53-57.

2) Rosin D. The history of surgery and minimnal access surgery. In: Rosin RD, editor. Minimal access medicine and surgery. Oxford: Radcliffe Medical Press; 1993. p.1-9.

3) Modlin IM, Kidd M, Lye KD. From the lumen to the laparoscope. Arch Surg 2004;139:1110-1126.

4) Nagy AG, Poulin EC, Girotti MJ, Litwin DE, Mamazza J. History of laparoscopic surgery. Can J Surg 1992;35:271-274.

5) Filipi C, Fitzgibbons R, Salerno G. Historical review: diagnostic laparoscopy to laparoscopic cholecystectomy and beyond. In: Zucker KA, Bailey RW, editors. Surgical laparoscopy. St Louis Mo.: Quality Medical Publishing; 1991. p.3-21.

6) Stellato TA. History of laparoscopic surgery. Surg Clin North Am 1992;72:997-1002.

7) Lau WY, Leow CK, Li AK. History of endoscopic and laparoscopic surgery. World J Surg 1997;21:444-453.

8) Reynolds W, Jr. The first laparoscopic cholecystectomy. JSLS 2001;5:89-94.

9) Hur SH, Lee SM, Koh SH, Hong SH, Oh SM. The Usefulness of Three-portal Technique for Laparoscopic Cholecystectomy. J Minim Invasive Surg 1999;2:41-48.

10) Kwon TS, Lee SM, Park SJ, et al. Clinical Application of $2 \mathrm{~mm}$ Trocar Mini-laparoscopic Cholecystectomy. J Minim Invasive Surg 2007;10:79-82.

11) Shin IS, Lee SM, Choi JY, et al. Initial Experience of Laparoscopic Totally Extraperitoneal Inguinal Hernia Repair. J Minim Invasive Surg 2007;10:89-93.

12) Jang JH, Lee SM, Choi SI, Joo SH, Hong SH. Total Laparoscopic Extraperitoneal Hernia Repair (TEP) Under Local Anesthesia: A Case Report. J Minim Invasive Surg 2008;11:158-160.

13) Bae YS, Lee SM, Kim JH, Kim BS, Joo SH. Laparoscopic Cholecystectomy in Patients with a History of Upper Abdominal Surgery. J Minim Invasive Surg 2009;12:108-112. 